\title{
Dose exploration results from Phase 1 study of cemiplimab, a human monoclonal programmed death (PD)-1 antibody, in Japanese patients with advanced malignancies
}

\author{
Shigehisa Kitano ${ }^{1}$ - Toshio Shimizu ${ }^{1} \cdot$ Takafumi Koyama $^{1} \cdot$ Takahiro Ebata $^{1} \cdot$ Satoru Iwasa ${ }^{1}$. Shunsuke Kondo ${ }^{1}$. \\ Akihiko Shimomura ${ }^{1} \cdot$ Yutaka Fujiwara ${ }^{1} \cdot$ Noboru Yamamoto $^{1} \cdot$ Anne Paccaly $^{2} \cdot$ Siyu Li $^{3} \cdot$ Petra Rietschel $^{2}$. \\ Tasha Sims ${ }^{2}$
}

Received: 29 May 2020 / Accepted: 30 September 2020 / Published online: 4 November 2020

(c) The Author(s) 2020

\begin{abstract}
Purpose Part 1 of this two-part, open-label, Phase 1 study (NCT03233139) assessed the safety, tolerability, pharmacokinetics, immunogenicity, and clinical activity of cemiplimab in Japanese patients with advanced malignancies.

Methods Patients received cemiplimab $250 \mathrm{mg}(n=6)$ or $350 \mathrm{mg}(n=7)$ every 3 weeks intravenously for up to 108 weeks in Part 1. Tumor responses were assessed by investigators every 9 weeks using the Response Evaluation Criteria in Solid Tumors version 1.1.

Results Of 13 patients enrolled, median age was 62 years (range 33-75) and eight patients were female. Median duration of cemiplimab exposure was 13.1 weeks (range 3.0-113.6). At the time of data cut-off, 11 patients $(84.6 \%$ ) had discontinued treatment (majority due to disease progression: $n=8,61.5 \%$ ). The most common treatment-emergent adverse events (TEAEs) of any grade were contact dermatitis, rash, and viral upper respiratory tract infection (each $n=3,23.1 \%$ ). Five grade $\geq 3$ TEAEs were reported in four patients: autoimmune colitis, dehydration, hyponatremia, hypophosphatemia, and muscular weakness. No dose-limiting toxicities were reported and no TEAEs led to death. Cemiplimab concentrations in serum were consistent with previously reported pharmacokinetic characteristics of cemiplimab. No anti-drug antibodies were detected in serum. Objective response rate [ORR; complete response + partial response (PR)] was 30.8\% (four PR) and disease control rate $[\mathrm{ORR}+$ stable disease (SD)] was $46.2 \%$ (6/13; two SD).

Conclusion Cemiplimab exhibited antitumor activity in Japanese patients with advanced malignancies. The safety profile was comparable to those previously reported for cemiplimab and other PD-1 inhibitors.
\end{abstract}

Trial registration NCT03233139 at ClinicalTrials.gov.

Electronic supplementary material The online version of this article (https://doi.org/10.1007/s00280-020-04161-6) contains supplementary material, which is available to authorized users.

Shigehisa Kitano

skitano@ncc.go.jp

1 Department of Experimental Therapeutics Koto-ku, National Cancer Center Hospital, 5-1-1, Tsukiji, Chuo-ku, Tokyo 104-0045, Japan

2 Regeneron Pharmaceuticals, Inc., Tarrytown, NY, USA

3 Regeneron Pharmaceuticals, Inc., Basking Ridge, NJ, USA 


\section{Graphic abstract}

\section{Dose exploration results from Phase 1 study of cemiplimab, a human monoclonal PD-1 antibody, in Japanese patients with advanced malignancies}
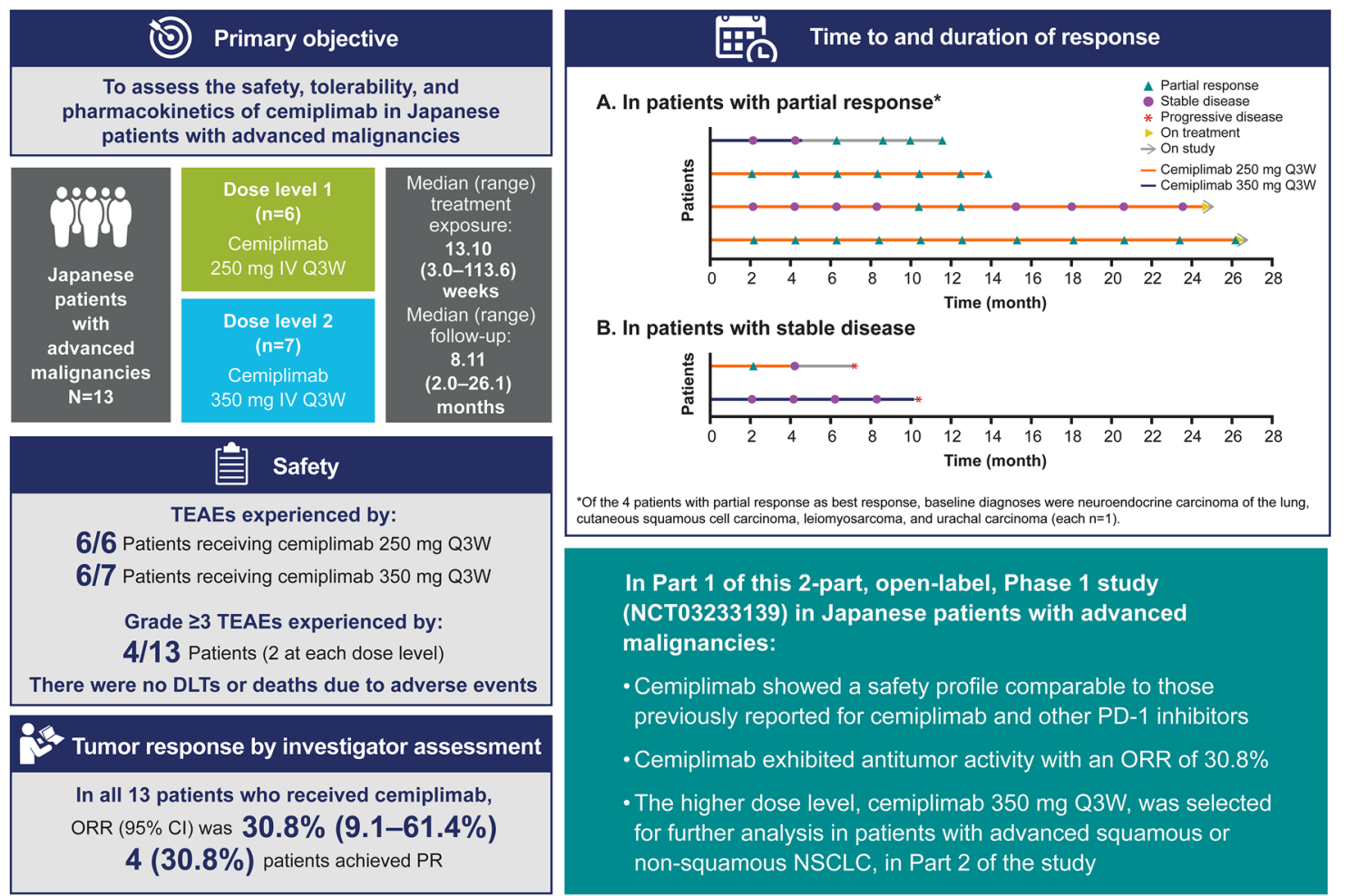

In Part 1 of this 2-part, open-label, Phase 1 study

(NCT03233139) in Japanese patients with advanced

malignancies:

- Cemiplimab showed a safety profile comparable to those

previously reported for cemiplimab and other PD-1 inhibitors

- Cemiplimab exhibited antitumor activity with an ORR of $30.8 \%$

- The higher dose level, cemiplimab 350 mg Q3W, was selected

for further analysis in patients with advanced squamous or

non-squamous NSCLC, in Part 2 of the study

CI, confidence interval; $D L T s$, dose-limiting toxicities; IV, intravenous;
TEAE, treatment-emergent adverse event (regardless of attribution).

Authors: Shigehisa Kitano, Toshio Shimizu, Takafumi Koyama, Takahiro Ebata, Satoru Iwasa, Shunsuke Kondo, Akihiko Shimomura, Yutaka Fujiwara, Noboru Yamamoto, Anne Paccaly, Siyu Li, Petra Rietschel, Tasha Sims. Correspondence: skitano@ncc.go.jp

Keywords Cemiplimab $\cdot$ Anti-PD-1 $\cdot$ Immunotherapy $\cdot$ Advanced tumors $\cdot$ Japanese patients

\section{Introduction}

Cemiplimab is a high affinity, human, hinge-stabilized IgG4 monoclonal antibody to the programmed death (PD)-1 receptor that potently blocks the interactions of PD-1 with PDligand (L)1 and PD-L2 [1, 2]. It binds to PD-1 with high affinity and specificity. In preclinical studies, cemiplimab does not induce antibody-dependent cell-mediated cytotoxicity or complement-dependent cytotoxicity [1]. As a human antibody, it has a lower risk of inducing anti-drug antibodies (ADAs) than murine/human chimeric or humanized antibody therapies; and, thus, can potentially minimize immunogenicity risks compared with those antibody therapies [3]. Indeed, relatively low incidence of ADA was observed with cemiplimab (1.3\%). This rate is comparable to, and in some cases numerically lower than, those observed with PD-1 or
PD-L1 inhibitors (pembrolizumab: 0.7-2.5\%; durvalumab: 2.9-6.6\%; avelumab: 4.1-5.9\%; nivolumab: $4.1-37.8 \%$; atezolizumab: 30-48\%) after single or combination therapy [3].

In patients outside of Japan, cemiplimab has demonstrated a safety profile comparable to those for other PD-1 inhibitors and substantial anti-tumor activity in advanced malignancies, including cutaneous squamous cell carcinoma (CSCC) and non-small cell lung cancer (NSCLC), in controlled clinical trials and an observational study $[2,4,5]$.

CSCC is the second most common skin cancer affecting Japanese and the worldwide population [6-9]. Until the emergence of PD-1 inhibitors, the prognosis was poor for patients with either locally advanced CSCC not amenable to surgery or metastatic CSCC [10-12]. Cemiplimab ("cemiplimab-rwlc" in the US) is the first therapy approved in the US, Europe, Canada, Australia, Brazil, Switzerland, and 
Israel for the treatment of patients with metastatic or locally advanced CSCC who are not candidates for curative surgery or curative radiation, with an objective response rate (ORR) of $47.2 \%[13,14]$. There is currently no approved therapy for CSCC in Japan. Most cases of CSCC in Japan are classified as high risk, warranting research of novel therapies [15].

High unmet needs for treatment of NSCLC exist both in Japan and worldwide. PD-1 inhibitors have quickly emerged as a treatment option with improved prognosis [16]. Interim data from a Phase 1 study of cemiplimab showed an acceptable safety profile and demonstrated antitumor activity in non-Japanese patients with NSCLC who had relapsed after or were refractory to first or further lines of therapy and for whom palliative radiotherapy was clinically indicated, which prompted pivotal trials of cemiplimab as monotherapy or in combination with other treatments in patients with stage IIIB, IIIC, or IV NSCLC [5].

This two-part Phase 1 study (NCT03233139) evaluates safety, tolerability, and pharmacokinetics (PK) of cemiplimab in Japanese patients with advanced malignancies. Tumor responses to cemiplimab treatment were also assessed. We report here dose exploration results from Part 1.

\section{Methods}

\section{Study design}

This two-part, open-label, Phase 1 study in Japanese patients comprises Part 1 of advanced malignancies treated with cemiplimab monotherapy [250 mg every 3 weeks (Q3W) or $350 \mathrm{mg}$ Q3W] and Part 2 of advanced squamous or nonsquamous NSCLC treated with cemiplimab (350 mg Q3W) alone or with standard of care platinum-based doublet chemotherapy for 2 cycles and ipilimumab $50 \mathrm{mg}$ every 6 weeks (Q6W) for up to four doses (Fig. 1). Part 1 was conducted at National Cancer Center Hospital, Tokyo, Japan. Part 2 is being conducted at multiple centers in Japan and consists of cohorts A (PD-L1 expression in tumor cells $\geq 50 \%$ ) and B (PD-L1 expression in tumor cells $<50 \%$ ). The data cut-off date of the dose exploration results in Part 1 reported here was September 6, 2019. Part 2 of the study is ongoing.

\section{Patients, treatment, and follow-up}

Adult patients 20 years of age or older were eligible for Part 1 enrollment. Key inclusion criteria for Part 1 were histologically or cytologically confirmed diagnosis of malignancy with no alternative standard of care therapeutic option; Eastern Cooperative Oncology Group (ECOG) performance status of 0 or 1; adequate hepatic, renal, and bone marrow functions. Adequate hepatic function was defined as total bilirubin $\leq 1.5 \times$ upper limit of normal (ULN) or $\leq 3 \times \mathrm{ULN}$ if liver metastases; aspartate aminotransferase (AST) and alanine aminotransferase (ALT) $\leq 3 \times$ ULN (or $\leq 5.0 \times$ ULN if liver metastases or hepatocellular carcinoma). Patients with hepatic metastases or hepatic malignancies were eligible for enrollment, unless with concomitant AST $\geq 3 \times \mathrm{ULN}$ and/or ALT $\leq 5 \times \mathrm{ULN}$, and total bilirubin of $1.5-3 \times$ ULN. Adequate renal function was defined as serum

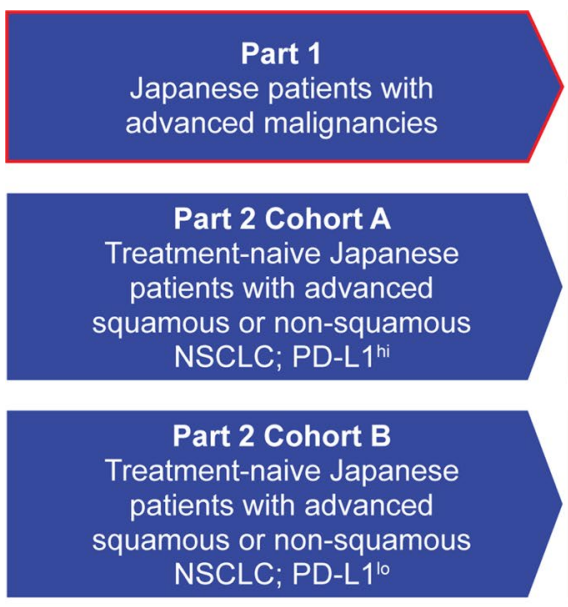

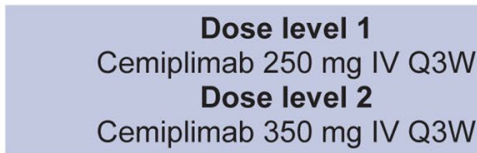

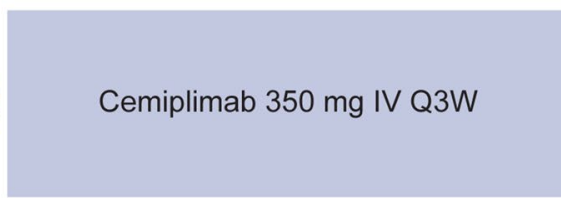

Cemiplimab 350 mg IV Q3W +

$\leq 4$ doses of ipilimumab $50 \mathrm{mg}$ $\mathrm{Q} 6 \mathrm{~W}+\leq 2$ cycles of

platinum-based doublet chemotherapy Q3W
Fig. 1 Study design. *Tumor responses were assessed using Response Evaluation Criteria in Solid Tumors version 1.1 by investigators in Part 1 and Part 2 Cohort B and by an independent central review committee in Part 2 Cohort A every 9 weeks in the first year, every 12 weeks in the second year, and every 8 weeks during the fol- low-up. IV intravenously, $N S C L C$ non-small cell lung cancer, $P D-L I$ programmed cell death-ligand $1, P D-L 1^{h i} \geq 50 \%$ PD-L1 expression in tumor cells, $P D-L l^{l o}<50 \%$ PD-L1 expression in tumor cells, $P K$ pharmacokinetics, $Q 3 W$ every 3 weeks, $Q 6 W$ every 6 weeks 
creatinine $\leq 1.5 \times$ ULN or creatinine clearance $>50 \mathrm{~mL} /$ min (or estimated glomerular filtration rate $>30 \mathrm{~mL} /$ $\min \times 1.73 \mathrm{~m}^{2}$ if renal cell carcinoma). Adequate bone marrow function was defined as hemoglobin $\geq 8.0 \mathrm{~g} / \mathrm{dL}$; absolute neutrophil count $\geq 1.5 \times 10^{9} / \mathrm{L}$; platelet count $\geq 75 \times 10^{9} / \mathrm{L}$. In addition, patients must have been born in Japan, and their biological parents and grandparents must be of Japanese origin.

Patients were excluded from Part 1 of the study if they received prior treatment targeting the PD-1/PD-L1 pathway. Additional key exclusion criteria included, but were not limited to: ongoing or recent autoimmune disease that required systemic immunosuppressive treatments; treatment with corticosteroids ( $>10 \mathrm{mg}$ prednisone daily or equivalent) within the first 4 weeks prior to the first dose of cemiplimab; active brain metastases; and active uncontrolled human immunodeficiency virus, hepatitis $\mathrm{C}$ virus, or hepatitis $\mathrm{B}$ virus infections.

All patients in Part 1 received cemiplimab $250 \mathrm{mg}$ or $350 \mathrm{mg}$ Q3W as a 30-min intravenous infusion on Day 1 of each treatment cycle for up to 2 years of treatment, or until completion of treatment or progression of disease, unacceptable toxicity, withdrawal of consent, or meeting of another study withdrawal criterion. Patients had a follow-up for up to 24 weeks after the treatment period.

\section{Objectives}

The primary objective of the study was to assess the safety, tolerability, and PK of cemiplimab in Japanese patients with advanced malignancies. The secondary objective of the study was to assess the immunogenicity of cemiplimab. The exploratory objective of Part 1 was to evaluate tumor response to cemiplimab monotherapy in patients with measurable disease.

\section{Assessments}

Severity of adverse events (AEs) was graded according to the National Cancer Institute Common Terminology Criteria for Adverse Events (version 4.03) [17]. The relatedness of AEs to treatment was assessed by investigators. PK of cemiplimab was assessed after the first dose. Trough and end-of-infusion concentrations of cemiplimab in serum were measured upon multiple dosing throughout the study using a validated enzyme-linked immunosorbent assay with a lower limit of quantification of $0.078 \mathrm{mg} / \mathrm{L}$. ADAs against cemiplimab in serum were measured at pre-dose and during treatment using a validated electrochemiluminescence bridging immunoassay. Tumor responses were assessed using Response Evaluation Criteria in Solid Tumors version 1.1 (RECIST 1.1) [18] by investigators in Part 1 every 9 weeks in the first year, every 12 weeks in the second year, and every 8 weeks during the 24 -week follow-up period.

\section{Statistical analysis}

No statistical hypothesis was tested in this observational study. For Part 1, the sample size of approximately 14 patients (up to seven patients per dose group) was selected based on modified $3+3$ design $(4+3)$. The safety and efficacy analysis sets included all patients who received at least one dose of cemiplimab.

\section{Results}

\section{Patients, treatment, and follow-up}

Of the 13 patients with advanced malignancies enrolled in Part 1, the median age was 62.0 years (range 33-75), eight patients $(61.5 \%)$ were female, the majority $(8 / 13$; $61.5 \%)$ had ECOG performance status of $0,12(92.3 \%)$ had prior cancer-related systemic therapy, seven $(53.8 \%)$ had prior cancer-related radiation, and nine $(69.2 \%)$ had prior cancer-related surgery (Table 1). Patients who received $350 \mathrm{mg} \mathrm{Q} 3 \mathrm{~W}$ were slightly older and had higher ECOG performance status versus those who received $250 \mathrm{mg} \mathrm{Q} 3 \mathrm{~W}$. At the time of data cut-off, 11 patients $(84.6 \%)$ discontinued treatment and two $(15.4 \%)$ remained on treatment. No patients completed treatment. The most common reason for treatment discontinuation was disease progression $(8 / 13,61.5 \%)$. Median number of administered doses of cemiplimab was 4.0 (range 1-36) and median duration of exposure was 13.10 weeks (range 3.0-113.6) (Supplementary Table 1). Median duration of follow-up at the time of data cut-off was 8.11 months (range 2.0-26.1).

\section{Safety}

Twelve patients (92.3\%) experienced at least one treatment-emergent AE (TEAE) of any grade, regardless of attribution of relatedness to study drug, during the treatment period (Table 2). TEAEs occurred in six patients $(100.0 \%)$ treated with cemiplimab $250 \mathrm{mg}$ Q3W and six (85.7\%) treated with $350 \mathrm{mg}$ Q3W. The most common TEAEs were contact dermatitis, rash, and viral upper respiratory tract infection (each 3/13; $23.1 \%)$. Four patients (30.8\%; two at each dose level) experienced a total of five grade $\geq 3$ TEAEs. Each of the following grade $\geq 3$ TEAEs occurred once (with investigator assessment of treatment relatedness): autoimmune colitis (250 $\mathrm{mg}$ Q3W; related to treatment), 
Table 1 Patient demographics and baseline characteristics

\begin{tabular}{|c|c|c|c|}
\hline & $\begin{array}{l}\text { Cemiplimab } \\
250 \mathrm{mg} \text { Q3W }(n=6)\end{array}$ & $\begin{array}{l}\text { Cemiplimab } \\
350 \text { mg Q3W }(n=7)\end{array}$ & $\begin{array}{l}\text { Total } \\
(N=13)\end{array}$ \\
\hline Median age, years (range) & $55.5(33-75)$ & $64.0(45-74)$ & $62.0(33-75)$ \\
\hline$\geq 65$ years, $n(\%)$ & $2(33.3)$ & $3(42.9)$ & $5(38.5)$ \\
\hline Female, $n(\%)$ & $3(50.0)$ & $5(71.4)$ & $8(61.5)$ \\
\hline \multicolumn{4}{|l|}{ ECOG performance status, $n(\%)$} \\
\hline 0 & $5(83.3)$ & $3(42.9)$ & $8(61.5)$ \\
\hline 1 & $1(16.7)$ & $4(57.1)$ & $5(38.5)$ \\
\hline \multicolumn{4}{|l|}{ Primary tumor site, $n(\%)$} \\
\hline Lung & $1(16.7)$ & $1(14.3)$ & $2(15.4)$ \\
\hline Bladder & $1(16.7)$ & 0 & $1(7.7)$ \\
\hline Breast & 0 & $1(14.3)$ & $1(7.7)$ \\
\hline Non-melanoma skin & $1(16.7)$ & 0 & $1(7.7)$ \\
\hline Urethra & 0 & $1(14.3)$ & $1(7.7)$ \\
\hline Uterus & $1(16.7)$ & 0 & $1(7.7)$ \\
\hline Ovary & $1(16.7)$ & 0 & $1(7.7)$ \\
\hline Prostate & 0 & $1(14.3)$ & $1(7.7)$ \\
\hline Pancreas & 0 & $1(14.3)$ & $1(7.7)$ \\
\hline Other & $1(16.7)$ & $2(28.6)$ & $3(23.1)$ \\
\hline Prior cancer-related radiation, $n(\%)$ & $3(50.0)$ & $4(57.1)$ & $7(53.8)$ \\
\hline Median number of prior cancer-related radiation (range) & $0.5(0-1)$ & $1.0(0-2)$ & $1.0(0-2)$ \\
\hline Prior cancer-related systemic therapy, $n(\%)$ & $5(83.3)$ & $7(100)$ & $12(92.3)$ \\
\hline Median number of prior cancer-related systemic therapy (range) & $3.0(0-15)$ & $3.0(1-9)$ & $3.0(0-15)$ \\
\hline Prior cancer-related surgery, $n(\%)$ & $4(66.7)$ & $5(71.4)$ & $9(69.2)$ \\
\hline Median number of prior cancer-related surgeries (range) & $1.5(0-5)$ & $1.0(0-5)$ & $1.0(0-5)$ \\
\hline
\end{tabular}

ECOG Eastern Cooperative Oncology Group, $Q 3 W$ every 3 weeks

dehydration (250 mg Q3W; related to treatment), hyponatremia (350 mg Q3W; unrelated to treatment), hypophosphatemia ( $250 \mathrm{mg} \mathrm{Q3W}$; unrelated to treatment), and muscular weakness (350 mg Q3W; related to treatment).

Ten patients $(76.9 \%)$ experienced at least one treatment-related AE of any grade by investigator assessment (Supplementary Table 2). The most common treatment-related AEs were rash $(3 / 13 ; 23.1 \%)$, increased AST, fatigue, and hyperthyroidism (each $2 / 13 ; 15.4 \%$ ). Five patients $(38.5 \%)$ experienced immune-related AEs of any grade. Two patients $(15.4 \%)$ experienced immune-related AEs of grade $\geq 3$ of autoimmune colitis and muscle weakness (each $1 / 13 ; 7.7 \%$ ); both were treated with steroids, which reduced the severity of the AEs. One additional grade $\geq 3$ treatment-related AE of dehydration occurred in the same patient who had grade $\geq 3$ autoimmune colitis. No dose-limiting toxicities were observed; maximum tolerated dose was not reached. No AEs led to death.

\section{Pharmacokinetics}

At steady state, mean cemiplimab concentration in serum at trough was $55.7 \mathrm{mg} / \mathrm{L}$ [standard deviation (SD) 21.8] in six Japanese patients dosed with $250 \mathrm{mg}$ Q3W cemiplimab. The median body weight of these patients was $59 \mathrm{~kg}$. The steady state mean cemiplimab concentrations in serum at trough was $82.6 \mathrm{mg} / \mathrm{L}$ (SD 1.6) in seven Japanese patients dosed with $350 \mathrm{mg}$ Q3W cemiplimab (Fig. 2; Supplementary Table 3 ). The median body weight of these patients was $55 \mathrm{~kg}$. Maximum cemiplimab concentrations in serum at steady state were $178 \mathrm{mg} / \mathrm{L}$ and $262 \mathrm{mg} / \mathrm{L}$ for the $250 \mathrm{mg}$ Q3W and $350 \mathrm{mg} \mathrm{Q} 3 \mathrm{~W}$ dosing regimens, respectively.

\section{Immunogenicity}

No ADAs were detected in serum samples collected in Part 1 of this study. 
Table 2 Treatment-emergen adverse events, regardless of attribution

\begin{tabular}{|c|c|c|c|}
\hline$n(\%)$ & $\begin{array}{l}\text { Cemiplimab } 250 \mathrm{mg} \\
\text { Q3W }(n=6)\end{array}$ & $\begin{array}{l}\text { Cemiplimab } \\
350 \mathrm{mg} \text { Q3W } \\
(n=7)\end{array}$ & Total $(N=13)$ \\
\hline Any & $6(100.0)$ & $6(85.7)$ & $12(92.3)$ \\
\hline Grade $\geq 3$ & $2(33.3)$ & $2(28.6)$ & $4(30.8)$ \\
\hline Serious & $1(16.7)$ & $1(14.3)$ & $2(15.4)$ \\
\hline Led to discontinuation & 0 & $1(14.3)$ & $1(7.7)$ \\
\hline With an outcome of death & 0 & 0 & 0 \\
\hline \multicolumn{4}{|l|}{ Occurred in any patient enrolled } \\
\hline Contact dermatitis & $1(16.7)$ & $2(28.6)$ & $3(23.1)$ \\
\hline Rash & $2(33.3)$ & $1(14.3)$ & $3(23.1)$ \\
\hline Viral upper respiratory tract infection & $2(33.3)$ & $1(14.3)$ & $3(23.1)$ \\
\hline Increased aspartate aminotransferase & $1(16.7)$ & $1(14.3)$ & $2(15.4)$ \\
\hline Diarrhea & $2(33.3)$ & 0 & $2(15.4)$ \\
\hline Fatigue & 0 & $2(28.6)$ & $2(15.4)$ \\
\hline Hyperthyroidism & $1(16.7)$ & $1(14.3)$ & $2(15.4)$ \\
\hline Hypophosphatemia & $2(33.3)$ & 0 & $2(15.4)$ \\
\hline Insomnia & $1(16.7)$ & $1(14.3)$ & $2(15.4)$ \\
\hline Oropharyngeal pain & $2(33.3)$ & 0 & $2(15.4)$ \\
\hline Pruritus & $2(33.3)$ & 0 & $2(15.4)$ \\
\hline Abdominal pain & $1(16.7)$ & 0 & $1(7.7)$ \\
\hline Increased alanine aminotransferase & 0 & $1(14.3)$ & $1(7.7)$ \\
\hline Arthralgia & $1(16.7)$ & 0 & $1(7.7)$ \\
\hline Autoimmune colitis & $1(16.7)$ & 0 & $1(7.7)$ \\
\hline Increased blood creatinine & $1(16.7)$ & 0 & $1(7.7)$ \\
\hline Increased blood thyroid stimulating hormone & 0 & $1(14.3)$ & $1(7.7)$ \\
\hline Constipation & 0 & $1(14.3)$ & $1(7.7)$ \\
\hline Contusion & $1(16.7)$ & 0 & $1(7.7)$ \\
\hline Cough & $1(16.7)$ & 0 & $1(7.7)$ \\
\hline Dehydration & $1(16.7)$ & 0 & $1(7.7)$ \\
\hline Bullous dermatitis & $1(16.7)$ & 0 & $1(7.7)$ \\
\hline Dry eye & 0 & $1(14.3)$ & $1(7.7)$ \\
\hline Dry mouth & $1(16.7)$ & 0 & $1(7.7)$ \\
\hline Dysgeusia & $1(16.7)$ & 0 & $1(7.7)$ \\
\hline Eye pruritus & 0 & $1(14.3)$ & $1(7.7)$ \\
\hline Increased gamma-glutamyltransferase & $1(16.7)$ & 0 & $1(7.7)$ \\
\hline Hypertension & $1(16.7)$ & 0 & $1(7.7)$ \\
\hline Hypoalbuminemia & $1(16.7)$ & 0 & $1(7.7)$ \\
\hline Hypomagnesemia & $1(16.7)$ & 0 & $1(7.7)$ \\
\hline Hyponatremia & 0 & $1(14.3)$ & $1(7.7)$ \\
\hline Hypothyroidism & $1(16.7)$ & 0 & $1(7.7)$ \\
\hline Inappropriate antidiuretic hormone secretion & 0 & $1(14.3)$ & $1(7.7)$ \\
\hline Influenza & 0 & $1(14.3)$ & $1(7.7)$ \\
\hline Decreased lymphocyte count & $1(16.7)$ & 0 & $1(7.7)$ \\
\hline Lymphopenia & 0 & $1(14.3)$ & $1(7.7)$ \\
\hline Muscular weakness & 0 & $1(14.3)$ & $1(7.7)$ \\
\hline Neutropenia & $1(16.7)$ & 0 & $1(7.7)$ \\
\hline Small intestinal obstruction & $1(16.7)$ & 0 & $1(7.7)$ \\
\hline Spinal column stenosis & $1(16.7)$ & 0 & $1(7.7)$ \\
\hline Tumor pain & $1(16.7)$ & 0 & $1(7.7)$ \\
\hline Upper respiratory tract infection & 0 & $1(14.3)$ & $1(7.7)$ \\
\hline Urticaria & 0 & $1(14.3)$ & $1(7.7)$ \\
\hline
\end{tabular}

$Q 3 W$ every 3 weeks 


\section{Clinical activity}

The ORR per investigator assessment was 50.0\% [95\% confidence interval (CI) $11.8-88.2 \%$ ] in patients who received cemiplimab $250 \mathrm{mg}$ Q3W, $14.3 \%$ (95\% CI 0.4-57.9\%) in patients who received cemiplimab $350 \mathrm{mg}$ Q3W, and 30.8\% (95\% CI 9.1-61.4\%) overall (Table 3). At the time of data cut-off, the disease control rate (DCR) was $46.2 \%$ (95\% CI 19.2-74.9\%) overall. Four patients (30.8\%) achieved partial response and two patients (15.4\%) achieved stable disease. Of the four patients with partial response as best response, baseline diagnoses were neuroendocrine carcinoma of the lung, CSCC, leiomyosarcoma, and urachal carcinoma (each $n=1$ ). Of the two patients with stable disease as best

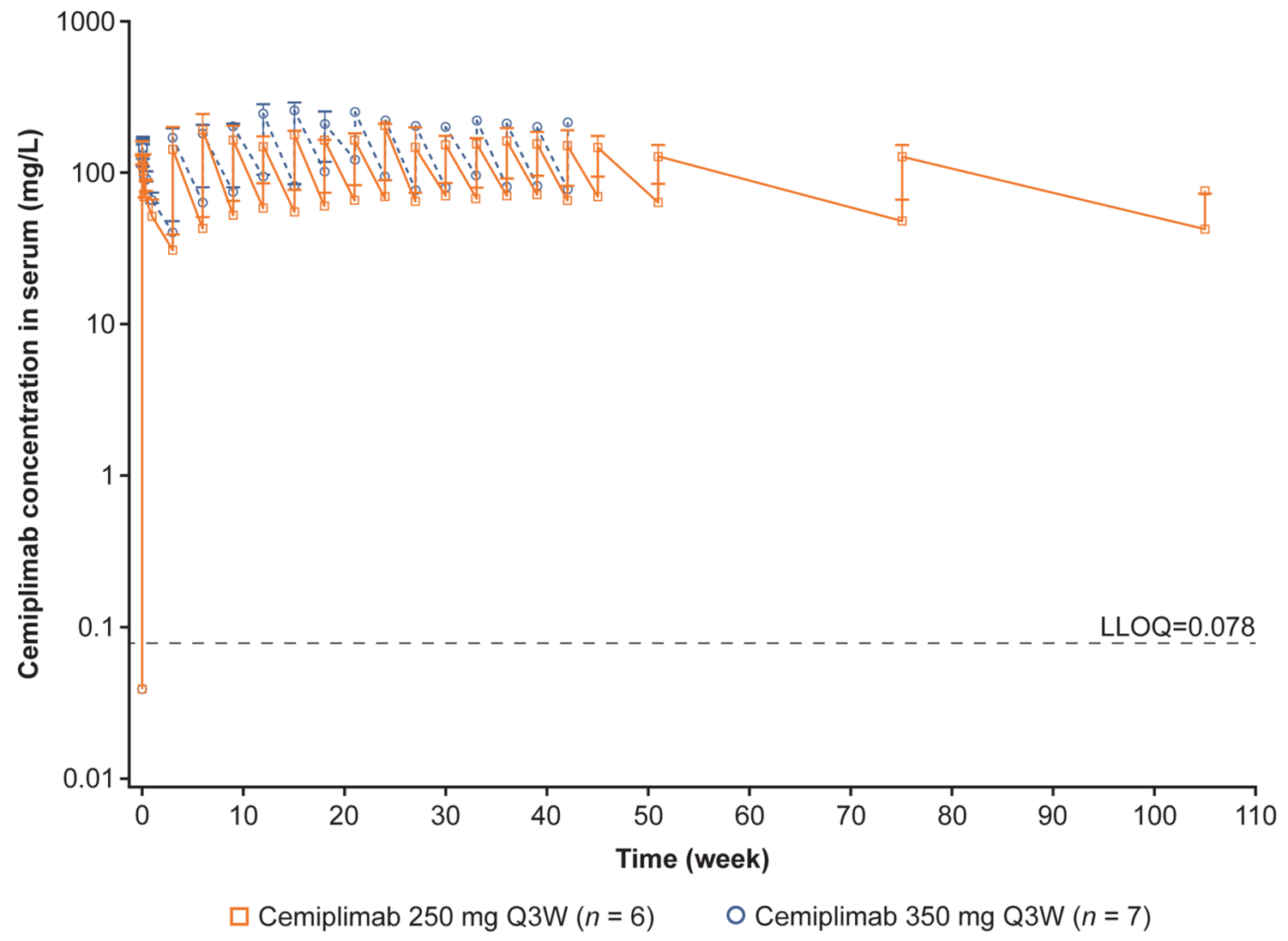

Fig. 2 Mean ( \pm standard deviation) of cemiplimab concentration in serum by time. $L L O Q$ lower limit of quantitation, $Q 3 W$ every 3 weeks

Table 3 Tumor response by investigator assessment

\begin{tabular}{llll}
\hline & $\begin{array}{l}\text { Cemiplimab } \\
250 \mathrm{mg} \text { Q3W } \\
(n=6)\end{array}$ & $\begin{array}{l}\text { Cemiplimab } \\
350 \mathrm{mg} \text { Q3W } \\
(n=7)\end{array}$ & Total $(N=13)$ \\
\hline Best overall tumor response, $n(\%)$ & & & \\
$\begin{array}{l}\text { Complete response } \\
\text { Partial response }\end{array}$ & 0 & 0 & 0 \\
Stable disease & $3(50.0)$ & $1(14.3)$ & $4(30.8)$ \\
Progressive disease & $1(16.7)$ & $1(14.3)$ & $2(15.4)$ \\
Objective response rate $^{\mathrm{a}}(95 \%$ confidence interval $)$ & $50.0(11.8-88.2)$ & $14.3(0.4-57.9)$ & $30.8(9.1-61.4)$ \\
Disease control rate $^{\mathrm{b}}(95 \%$ confidence interval $)$ & $66.7(22.3-95.7)$ & $28.6(3.7-71.0)$ & $46.2(19.2-74.9)$ \\
\hline
\end{tabular}

${ }^{a}$ Including patients with complete or partial response confirmed by repeated assessments $\geq 4$ weeks apart

${ }^{b}$ Including patients with complete response, partial response, or stable disease; stable disease criteria were met at least once $\geq 39$ days after first dose

$Q 3 W$ every 3 weeks 
response, baseline diagnoses were squamous-cell carcinoma of unknown primary and ovarian cancer (each $n=1$ ).

The best percent change in the sum of target lesion diameters from baseline based on investigator assessment for 11 patients who had at least one response evaluation showed tumor response to cemiplimab (Supplementary Fig. 1). Responses to cemiplimab appeared to be deep and durable (Fig. 3; Supplementary Fig. 2).

\section{Discussion}

In Part 1 of this Phase 1 study in Japanese patients, cemiplimab showed an acceptable safety profile comparable to those reported with cemiplimab in non-Japanese patients and with other PD-1 inhibitors. Anti-tumor activity of cemiplimab in advanced malignancies was observed.

\section{Safety}

The safety profile of cemiplimab observed in this Japanese study is consistent with that in non-Japanese studies. For example, in the cemiplimab first-in-human study, where 58 non-Japanese patients with advanced solid tumors received 1,3 , or $10 \mathrm{mg} / \mathrm{kg}$ cemiplimab Q2W (40 of these patients in the study received cemiplimab in combination with hypofractionated radiation), no dose-limiting toxicities were observed. The most common treatment-related AEs were fatigue $(n=14 ; 24.1 \%)$, arthralgias $(n=7 ; 12.1 \%)$, and nausea $(n=6 ; 10.3 \%)$. Treatment-related AEs of grade $\geq 3$ were transaminase elevation $(n=2)$, anemia $(n=1)$, and anti-Hu associated paraneoplastic encephalitis $(n=1)$ [19]. In a pivotal Phase 2 study (EMPOWER-CSCC 1), 115 non-Japanese patients with metastatic CSCC received cemiplimab monotherapy, either at $350 \mathrm{mg}$ Q3W or $3 \mathrm{mg} / \mathrm{kg}$ Q2W. Of these, 113 patients $(98.3 \%)$ experienced TEAEs and the most common TEAEs were fatigue $(n=31 ; 27 \%)$, diarrhea $(n=27$; $23.5 \%)$, and nausea $(n=24 ; 20.9 \%)$. Grade $\geq 3$ TEAEs occurred in 52 patients $(45.2 \%)$. A total of 82 patients (71.3\%) experienced treatment-related AEs of any grade and 16 patients (13.9\%) experienced treatment-related AEs of grade $\geq 3$ [20]. Among 21 non-Japanese patients with NSCLC who received 1, 3, or $10 \mathrm{mg} / \mathrm{kg}$ Q2W or $200 \mathrm{mg}$ Q2W cemiplimab, the most common treatment-related AEs were asthenia, pneumonitis, and rash (each $n=3 ; 14.3 \%$ ). Each of the following grade $\geq 3$ treatment-related AEs occurred once: pneumonitis, diabetic ketoacidosis, and nephritis [5]. In 20 non-Japanese patients with recurrent or metastatic cervical cancer who received cemiplimab $3 \mathrm{mg} /$ $\mathrm{kg}$ Q2W as monotherapy or in combination with hypofractionated radiation, the most common TEAEs of any grade were diarrhea $(n=4 ; 40.0 \%)$, fatigue, hypokalemia and pain in extremity (each $n=3 ; 30.0 \%$ ) in the monotherapy cohort, and diarrhea and urinary tract infection (each $n=3 ; 30.0 \%$ )

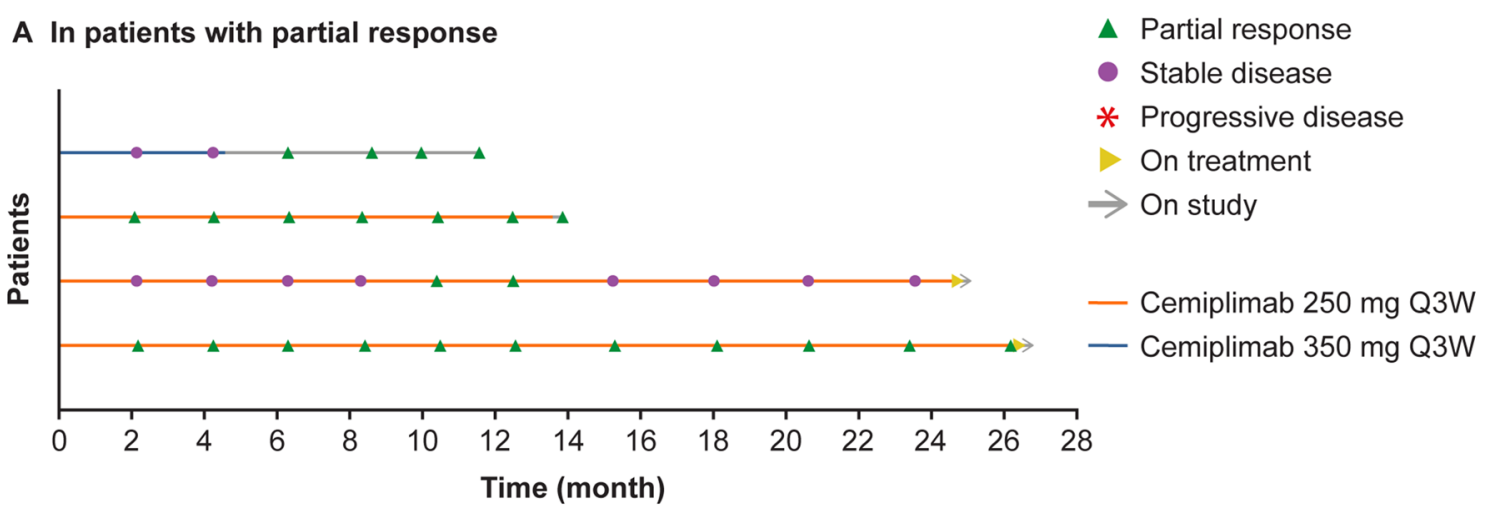

B In patients with stable disease

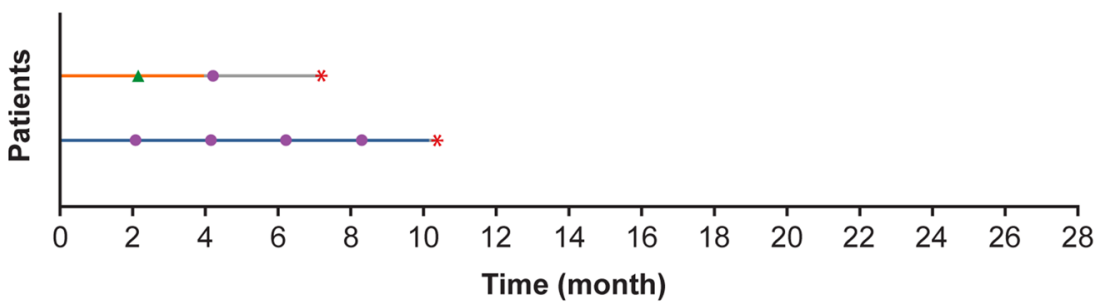

Fig. 3 Time to and duration of response in responding patients. Plot shows time to and duration of response in a four patients with confirmed partial response and $\mathbf{b}$ two patients with stable disease. $Q 3 W$ every 3 weeks 
in the cemiplimab and hypofractionated radiation combination cohort [21]. No new safety signals were observed in Japanese patients.

In Japanese patient populations, the safety profile of cemiplimab is comparable to those of other PD-1 and PD-L1 inhibitors [22-24]. In a nivolumab study in 35 Japanese patients with advanced or recurrent squamous NSCLC conducted at 17 sites, 24 patients $(68.6 \%)$ experienced treatment-related AEs of any grade and two (5.7\%) experienced grade $\geq 3$ treatment-related AEs [22]. Similarly, treatment-related AEs were reported in eight patients (80\%) in a Phase 1 Japanese study of pembrolizumab in advanced solid tumors [23]. In a small dose exploration study of atezolizumab, a PD-L1 inhibitor, TEAEs occurred in all six Japanese patients with advanced solid tumors. Two patients experienced treatment-related AEs (influenza-like illness and increased alkaline phosphatase; one patient each) that led to suspension of study treatment [24].

In this Japanese study, two patients (15.4\%) experienced grade $\geq 3$ immune-related AEs with cemiplimab, which is consistent with data reported for non-Japanese patients. For instance, in an open-label, Phase 2 study, comprising 78 non-Japanese patients with locally advanced CSCC receiving cemiplimab $3 \mathrm{mg} / \mathrm{kg}$ Q2W, eight patients (10.3\%) experienced grade $\geq 3$ immune-related AEs [25]. Moreover, the incidence of grade $\geq 3$ immune-related AEs with cemiplimab seems either comparable, or numerically lower than those observed with other PD-1 inhibitors in Japanese patient populations. In a retrospective analysis comprising 47 Japanese patients with metastatic renal cell carcinoma treated with nivolumab, 10 patients (21.3\%) experienced grade $\geq 3$ immune-related AEs [26]. Similarly, in a Phase 1 study of 42 Japanese patients with advanced melanoma treated with pembrolizumab, 13 (31.0\%) patients experienced grade $\geq 3$ immune-related AEs [27].

\section{Pharmacokinetics}

The cemiplimab concentrations observed in this Japanese study were slightly higher than those observed in non-Japanese patients with advanced malignancies in previous studies, where $C_{\text {trough }}$ of $58.7 \mathrm{mg} / \mathrm{L}$ and $C_{\text {eoi }}$ of $166 \mathrm{mg} / \mathrm{L}$ were predicted at $350 \mathrm{mg}$ Q3W at steady state by post hoc analysis $[28,29]$. Considering an average body weight of $59 \mathrm{~kg}$ for the Japanese patients in the $250 \mathrm{mg}$ Q $3 \mathrm{~W}$ cohort and $55 \mathrm{~kg}$ in the $350 \mathrm{mg}$ Q3W cohort, compared with an average body weight of $75 \mathrm{~kg}$ in previous non-Japanese studies, these findings were expected since a fixed dosing regimen generated slightly higher cemiplimab concentrations in serum in patients with lower body weight $[28,29]$. The impact of the higher concentrations in serum on efficacy and safety was minimal considering the wide therapeutic margin, as evidenced by relatively flat exposure-response relationships for both efficacy and safety, observed in cemiplimab and other PD-1 inhibitors [2, 30, 31]. These findings are also consistent with observations from Japanese versus non-Japanese studies of pembrolizumab and of atezolizumab [23, 24]. In addition, model-based population PK covariate analysis demonstrated that the PK of cemiplimab, nivolumab, and pembrolizumab was generally unaffected by race or geographic region [28, 29, 32, 33].

\section{Immunogenicity}

ADA may induce infusion-related reactions or alter the PK of a PD-1 inhibitor by affecting clearance, which in turn could affect clinical activity [3, 34]. In this study, all serum samples tested negative for ADA. No infusion-related reactions were reported and response to cemiplimab treatment appeared durable. These observations agree with the minimal immunogenicity against cemiplimab observed in nonJapanese patients, in which the incidence of ADAs was $1.3 \%$ with $0.3 \%$ persistent ADA responses [14]. A review article showed that, among 10 immunogenicity analyses of nivolumab, pembrolizumab, and cemiplimab, a low incidence of ADA (0-12.7\%) has been reported following single-agent treatment [3].

\section{Clinical activity}

In this study, cemiplimab has shown clinical activity in a difficult-to-treat patient population with advanced malignancies and no alternative standard of care therapeutic option. Evidence for deep and durable tumor responses to cemiplimab was emerging. Both dosing regimens tested in this study appeared efficacious in Japanese patients. Although the ORR observed with the $250 \mathrm{mg}$ Q3W dosing regimen was numerically higher than that with the $350 \mathrm{mg}$ Q3W dosing regimen, there was significant overlap in the $95 \%$ CIs, indicating similar clinical activity. In addition, the slightly younger age and slightly lower ECOG performance status in the $250 \mathrm{mg}$ Q3W versus $350 \mathrm{mg}$ Q3W dosing groups, combined with a small patient population with diverse tumor types, might lead to high variability in clinical activity results.

The clinical activity of cemiplimab in this study is consistent with clinical activity observed in non-Japanese patient populations. In 43 non-Japanese patients with advanced solid tumors who received 1,3 , or $10 \mathrm{mg} / \mathrm{kg}$ Q2W, or 1 or $3 \mathrm{mg} / \mathrm{kg}$ Q2W cemiplimab in combination with hypofractionated radiation, partial/unconfirmed partial responses were observed in nine of 22 patients $(40.9 \%)$ who received combination therapy and in two of 21 patients $(9.5 \%)$ who received cemiplimab monotherapy; disease control was achieved in 27 of 43 patients (62.8\%) [19]. In non-Japanese patients with metastatic CSCC treated with $350 \mathrm{mg}$ Q3W or $3 \mathrm{mg} / \mathrm{kg}$ Q2W cemiplimab, the ORR and DCR were $44.3 \%$ 
(95\% CI 33.7-53.9\%) and 67.0\% (95\% CI 57.6-75.4\%), respectively, compared to an ORR of $30.8 \%$ (95\% CI 9.1-61.4\%) and a DCR of $46.2 \%$ (95\% CI $19.2-74.9 \%$ ) in this study [20]. In non-Japanese patients with locally advanced CSCC who received $3 \mathrm{mg} / \mathrm{kg}$ Q2W cemiplimab, the ORR and DCR were $43.6 \%$ (95\% CI 32.4-55.3\%) and 79.5\% (95\% CI 68.8-87.8\%), respectively [35]. In non-Japanese patients with metastatic or locally advanced CSCC who received cemiplimab $3 \mathrm{mg} / \mathrm{kg}$ Q2W in a Phase 1 study, the ORR and DCR were 50\% (95\% CI 30-70\%) and 65\% (95\% CI 44-83\%), respectively [2]. In addition, the ORR and DCR were $28.6 \%$ and $57.1 \%$, respectively, in non-Japanese patients with NSCLC who received 1, 3, or $10 \mathrm{mg} / \mathrm{kg}$ Q2W or $200 \mathrm{mg}$ Q2W cemiplimab [5]. In an analysis of 20 nonJapanese patients with recurrent or metastatic cervical cancer who received cemiplimab $3 \mathrm{mg} / \mathrm{kg}$ Q2W as monotherapy or in combination with hypofractionated radiation, ORR was $10.0 \%$ with both responders achieving ongoing responses of $>3.7$ months at the time of data cut-off [21].

In Japanese patient populations, the clinical activity of cemiplimab is similar to those of other PD-1 inhibitors. Among 10 Japanese patients with advanced solid tumors in a Phase 1 study, partial responses determined by investigators according to RECIST 1.1 were observed in two patients (22.2\%) treated with pembrolizumab $10 \mathrm{mg} / \mathrm{kg}$ Q2W; one patient (a 91-year-old man) had metastatic melanoma, and the other (a 53-year-old man) had NSCLC [23]. In a Phase 1 study of nivolumab in 17 Japanese patients with malignant solid tumors, complete response was observed in one patient with melanoma; partial response was observed in two patients (one with colorectal cancer; one with thyroid cancer); stable disease was observed in three patients (two with NSCLC; one with thymic cancer) [36]. In Japanese patients with previously untreated advanced melanoma who received nivolumab treatment, the ORR and DCR were $43.5 \%$ (90\% CI: $28.1-60.3 \%$ ) and $78.3 \%$ (90\% CI: 61.6-89.0\%), respectively [37].

PD-1 inhibitors, including cemiplimab, have shown remarkable clinical activity in Japanese and non-Japanese patients who progress after receiving previously established standard of care.

\section{Dose selection}

The higher dose level, $350 \mathrm{mg}$ Q3W, was selected for further analysis in Part 2 based on three considerations: similar safety profiles were observed between the two dosing regimens in Japanese patients; the significant overlap in the 95\% CIs of ORRs for $250 \mathrm{mg}$ Q3W and $350 \mathrm{Q} 3 \mathrm{~W}$ indicated similar clinical activity; cemiplimab dose exploration in non-Japanese patients supported approval of the $350 \mathrm{mg} \mathrm{Q} 3 \mathrm{~W}$ dosing regimen for patients with metastatic or locally advanced CSCC who are not candidates for curative surgery or curative radiation in the US, Europe, Canada, Australia, Brazil, Switzerland, and Israel [13, 14, 28, 29]. This cemiplimab $350 \mathrm{mg}$ Q3W dosing regimen has been selected for further development as monotherapy and in combination across disease indications.

\section{Study limitations}

The number of patients in this Japanese study was limited. However, observations of this study in Japanese patients were generally consistent with those of previous studies in non-Japanese patients. The follow-up period of this study was relatively short as of data cut-off. Evidence of durable tumor response was emerging and will be further evaluated via longer follow-up.

\section{Future development}

The acceptable safety profile and clinical activity observed in this Japanese study have demonstrated cemiplimab as a promising treatment option for patients with difficult-to-treat advanced malignancies and no alternative standard of care therapeutic option. Considering the observations from Japanese and global studies across multiple tumor types [2, 5, 21], cemiplimab alone or in combination is being developed for the treatment of basal cell carcinoma, lung cancer, and cervical cancer, among others.

Acknowledgements The authors would like to thank the patients, their families, all other investigators, and all investigational site members involved in this study. Medical writing support was provided by $\mathrm{Bu}$ Reinen, PhD, of Prime, Knutsford, UK, funded by Regeneron Pharmaceuticals, Inc. and Sanofi according to Good Publication Practice guidelines (https://www.acpjournals.org/doi/10.7326/M15-0288). The authors were responsible for all content and editorial decisions, and received no honoraria related to the development of this publication.

Funding The study was funded by Regeneron Pharmaceuticals, Inc. and Sanofi.

\section{Compliance with ethical standards}

Conflict of interest SK: Research grants from Regeneron Pharmaceutical, Inc. during the conduct of the study; personal lecture fees from Sanofi, Nippon Kayaku, Meiji Seika Pharma, Taiho, Celgene, and Sumitomo Dainippon Pharma; personal lecture and advisory board fees from AstraZeneca, Chugai, Pfizer, Boehringer Ingelheim, Novartis, Daiichi-Sankyo, MSD, Kyowa Hakko Kirin, Ono Pharmaceutical Co., Ltd., and Bristol-Myers Squibb; research grants and personal lecture and advisory board fees from Eisai; research grants from Astellas, Gilead Sciences, AMED (Japan Agency for Medical Research and Development), and JSPS (Japan Society for the Promotion of Science). TS: Institutional research expenses from Regeneron Pharmaceuticals, Inc. during the conduct of the study; institutional research expenses from Novartis, Eli Lilly, AbbVie, AstraZeneca, Eisai, Astellas, Chordia Therapeutics, Bristol-Myers Squibb, Daiichi-Sankyo, MilleniamTakeda, PharmaMar, FivePrime, 3D-Medicine and Symbio-Pharma, 
advisory role personal fees from Milleniam-Takeda, personal lecture fees from Boehringer Ingelheim, Taiho Pharma, Chugai Pharmaceutical, Co., Ltd., Ono Pharmaceutical Co., Ltd., Ono Pharma Taiwan Co., Ltd., outside the submitted work. TK, TE, SI, SK, AS: No conflict of interest declared. YF: Research funding grants from Abbie, AstraZeneca, Bristol-Myers Squibb, Chugai, Daiichi-Sankyo, Eisai, Eli Lilly, Incyte, Merck Serono, MSD, and Novartis; advisory role personal fees from AstraZeneca, Bristol-Myers Squibb, Novartis, and Ono Pharmaceutical Co., Ltd., speaker's bureau personal fees from Bristol-Myers Squibb, Ono Pharmaceutical Co., Ltd., and Taiho, all outside of the submitted work. NY: Research grants from Chugai, Taiho, Eisai, Lilly, Quintiles, Astellas, Bristol-Myers Squibb, Novartis, Daiichi-Sankyo, Pfizer, Boehringer Ingelheim, Kyowa-Hakko Kirin, Bayer, Ono Pharmaceutical Co., Ltd. and Takeda; honoraria from Ono Pharmaceutical Co., Ltd., Chugai, AstraZeneca, Pfizer, Lilly, Bristol-Myers Squibb; and consulting fees from Eisai, Otsuka, Takeda, and Boehringer Ingelheim, outside the submitted work. AP, SL, PR, TS: Employee and shareholder of Regeneron Pharmaceuticals, Inc.

Statement of human and animal rights This study was conducted in accordance with the principles of the Declaration of Helsinki and the International Conference on Harmonization Guidelines for Good Clinical Practice. The study protocol was approved by ethics committees.

Informed consent Informed consent was obtained from all individual participants included in the study. This article does not report data from animals performed by any of the authors.

Data sharing Qualified researchers may request access to study documents (including the clinical study report, study protocol with any amendments, blank case report form, statistical analysis plan) that support the methods and findings reported in this manuscript. Individual anonymized participant data will be considered for sharing once the product and indication has been approved by major health authorities (e.g., FDA, EMA, PMDA, etc.), if there is legal authority to share the data and there is not a reasonable likelihood of participant re-identification. Submit requests to https://vivli.org/.

Open Access This article is licensed under a Creative Commons Attribution 4.0 International License, which permits use, sharing, adaptation, distribution and reproduction in any medium or format, as long as you give appropriate credit to the original author(s) and the source, provide a link to the Creative Commons licence, and indicate if changes were made. The images or other third party material in this article are included in the article's Creative Commons licence, unless indicated otherwise in a credit line to the material. If material is not included in the article's Creative Commons licence and your intended use is not permitted by statutory regulation or exceeds the permitted use, you will need to obtain permission directly from the copyright holder. To view a copy of this licence, visit http://creativecommons.org/licenses/by/4.0/.

\section{References}

1. Burova E, Hermann A, Waite J, Potocky T, Lai VSH, Liu M, Allbritton O, Woodruff A, Wu Q, D'Orvilliers A, Garnova E, Rafique A, Poueymirou W, Martin J, Huang T, Skokos D, Kantrowitz J, Popke J, Mohrs M, MacDonald D, Ioffe E, Olson W, Lowy I, Murphy A, Thurston G (2017) Characterization of the anti-PD-1 antibody REGN2810 and its antitumor activity in human PD-1 knock-in mice. Mol Cancer Ther 16(5):861-870. https://doi. org/10.1158/1535-7163.MCT-16-0665
2. Migden MR, Rischin D, Schmults CD, Guminski A, Hauschild A, Lewis KD, Chung CH, Hernandez-Aya L, Lim AM, Chang ALS, Rabinowits G, Thai AA, Dunn LA, Hughes BGM, Khushalani NI, Modi B, Schadendorf D, Gao B, Seebach F, Li S, Li J, Mathias M, Booth J, Mohan K, Stankevich E, Babiker HM, Brana I, Gil-Martin M, Homsi J, Johnson ML, Moreno V, Niu J, Owonikoko TK, Papadopoulos KP, Yancopoulos GD, Lowy I, Fury MG (2018) PD-1 blockade with cemiplimab in advanced cutaneous squamous-cell carcinoma. N Engl J Med 379(4):341-351. https ://doi.org/10.1056/NEJMoa1805131

3. Davda J, Declerck P, Hu-Lieskovan S, Hickling TP, Jacobs IA, Chou J, Salek-Ardakani S, Kraynov E (2019) Immunogenicity of immunomodulatory, antibody-based, oncology therapeutics. J Immunother Cancer 7(1):105. https://doi.org/10.1186/s4042 5-019-0586-0

4. Papadopoulos KP, Johnson ML, Lockhart AC, Moore K, Falchook GS, Formenti SC, Naing A, Carvajal RD, Rosen LS, Weiss GJ, Leidner RS, Li J, Paccaly A, Feng M, Stankevich E, Lowy I, Fury MG, Crittenden MR (2020) First-in-human study of cemiplimab alone or in combination with radiotherapy and/or low-dose cyclophosphamide in patients with advanced malignancies. Clin Cancer Res 26(5):1025-1033. https://doi.org/10.1158/1078-0432. CCR-19-2609

5. Moreno Garcia V, Calvo E, Olmedo Garcia ME, Gil Martin M, Aljumaily R, Papadopoulos KP, Rosen LS, Rietschel P, Mohan KK, Li J (2019) Tolerability and antitumor activity of cemiplimab, a human monoclonal anti-PD-1, in patients with non-small cell lung cancer (NSCLC): interim data from phase 1 dose escalation and NSCLC expansion cohort. J Clin Oncol 37(suppl 8; abstr 116). https://doi.org/10.1200/JCO.2019.37.8_suppl.116

6. Lomas A, Leonardi-Bee J, Bath-Hextall F (2012) A systematic review of worldwide incidence of nonmelanoma skin cancer. Br J Dermatol 166(5):1069-1080. https://doi.org/10.111 1/j.1365-2133.2012.10830.x

7. Rogers HW, Weinstock MA, Feldman SR, Coldiron BM (2015) Incidence estimate of nonmelanoma skin cancer (keratinocyte carcinomas) in the US population, 2012. JAMA Dermatol 151(10):1081-1086. https://doi.org/10.1001/jamadermat ol.2015.1187

8. Ishihara K, Saida T, Otsuka F, Yamazaki N (2008) Statistical profiles of malignant melanoma and other skin cancers in Japan: 2007 update. Int J Clin Oncol 13(1):33-41

9. Nishi M (2016) Epidemiology of skin cancer in Japan. Journal of Tumor 4(2):369-373

10. Karia PS, Han J (2012) Schmults CD (2013) Cutaneous squamous cell carcinoma: estimated incidence of disease, nodal metastasis, and deaths from disease in the United States. J Am Acad Dermatol 68(6):957-966. https://doi.org/10.1016/j.jaad.2012.11.037

11 Weinberg AS, Ogle CA, Shim EK (2007) Metastatic cutaneous squamous cell carcinoma: an update. Dermatol Surg 33(8):885-899

12. Schmults CD (2016) High-risk cutaneous squamous cell carcinoma: a practical guide for patient management. Springer, Berlin

13. European Medicines Agency (2019) LIBTAYO ${ }^{\circledR}$ EPAR. https ://www.ema.europa.eu/en/medicines/human/EPAR/libtayo. Accessed 22 May 2020

14. Regeneron Pharmaceuticals, Inc. (2018) LIBTAYO ${ }^{\circledR}$ [cemiplimab-rwlc] injection full US prescribing information. Regeneron Pharmaceuticals, Inc. https://www.accessdata.fda.gov/drugsatfda _docs/label/2018/761097s000lbl.pdf. Accessed 22 May 2020

15. Umebayashi Y, Akama T, Manabe M (2012) Most cases of cutaneous squamous cell carcinoma in Japan are classified as "high risk" according to the Japanese guideline. J Dermatol 39(9):812-814. https://doi.org/10.1111/j.1346-8138.2011.01419

16. Reck M, Rodríguez-Abreu D, Robinson AG, Hui R, Csôszi T, Fülöp A, Gottfried M, Peled N, Tafreshi A, Cuffe S (2016) 
Pembrolizumab versus chemotherapy for PD-L1-positive nonsmall-cell lung cancer. N Engl J Med 375(19):1823-1833. https ://doi.org/10.1056/NEJMoa1606774

17. US Department of Health Human Services (2016) Common terminology criteria for adverse events (CTCAE) version 4.03. 2010, USA: National Institutes of Health, National Cancer Institute. https://www.eortc.be/services/doc/ctc/CTCAE_4.03_2010-0614_QuickReference_5x7.pdf. Accessed 22 May 2020

18. Eisenhauer EA, Therasse P, Bogaerts J, Schwartz LH, Sargent D, Ford R, Dancey J, Arbuck S, Gwyther S, Mooney M, Rubinstein L, Shankar L, Dodd L, Kaplan R, Lacombe D, Verweij J (2009) New response evaluation criteria in solid tumours: revised RECIST guideline (version 1.1). Eur J Cancer 45(2):228-247. https://doi.org/10.1016/j.ejca.2008.10.026

19. Papadopoulos KP, Crittenden MR, Johnson ML, Lockhart AC, Moore KN, Falchook GS, Formenti S, Carvajal RD, Leidner RS, Naing A (2016) A first-in-human study of REGN2810, a monoclonal, fully human antibody to programmed death-1 (PD-1), in combination with immunomodulators including hypofractionated radiotherapy (hfRT). J Clin Oncol 34(suppl; abstr 3024)

20. Rischin D, Lim AM, Schmults C, Khushalani NI, Hughes BG, Schadendorf D, Dunn L, Chang AL, Hauschild A, Ulrich C, Eigentler T, Migden MR, Pavlick AC, Geiger J, Stankevich E, Li S, Lowy I, Fury M, Guminski A (2019) Phase 2 study of 2 dosing regimens of cemiplimab, a human monoclonal anti-PD-1, in metastatic cutaneous squamous cell carcinoma (mCSCC). Ann Oncol 30(suppl_5):v533-v563. https://doi.org/10.1093/annonc/ mdz255

21. Rischin D, Gil-Martin M, González-Martín A, Brana I, Hou J, Cho D, Falchook G, Formenti S, Jabbour S, Moore K (2018) 958P Cemiplimab, a human PD-1 monoclonal antibody, in patients (pts) with recurrent or metastatic cervical cancer: interim data from phase I cohorts. Ann Oncol 29(suppl 8):viii342-viii343. https:// doi.org/10.1093/annonc/mdy285

22. Hida T, Nishio M, Nogami N, Ohe $Y$, Nokihara H, Sakai H, Satouchi M, Nakagawa K, Takenoyama M, Isobe H (2017) Efficacy and safety of nivolumab in Japanese patients with advanced or recurrent squamous non-small cell lung cancer. Cancer Sci 108(5):1000-1006. https://doi.org/10.1111/cas.13225

23. Shimizu T, Seto T, Hirai F, Takenoyama M, Nosaki K, Tsurutani J, Kaneda H, Iwasa T, Kawakami H, Noguchi K (2016) Phase 1 study of pembrolizumab (MK-3475; anti-PD-1 monoclonal antibody) in Japanese patients with advanced solid tumors. Invest New Drugs 34(3):347-354. https://doi.org/10.1007/s1063 7-016-0347-6

24. Mizugaki H, Yamamoto N, Murakami H, Kenmotsu H, Fujiwara Y, Ishida Y, Kawakami T, Takahashi T (2016) Phase I dosefinding study of monotherapy with atezolizumab, an engineered immunoglobulin monoclonal antibody targeting PD-L1, in Japanese patients with advanced solid tumors. Invest New Drugs 34(5):596-603. https://doi.org/10.1007/s10637-016-0371-6

25. Migden MR, Khushalani NI, Chang ALS, Lewis KD, Schmults CD, Hernandez-Aya L, Meier F, Schadendorf D, Guminski A, Hauschild A, Wong DJ, Daniels GA, Berking C, Jankovic V, Stankevich E, Booth J, Li S, Weinreich DM, Yancopoulos GD, Lowy I, Fury MG, Rischin D (2020) Cemiplimab in locally advanced cutaneous squamous cell carcinoma: results from an open-label, phase 2, single-arm trial. Lancet Oncol 21:294-305. https://doi.org/10.1016/S1470-2045(19)30728-4

26. Ishihara $\mathrm{H}$, Takagi $\mathrm{T}$, Kondo $\mathrm{T}$, Homma $\mathrm{C}$, Tachibana $\mathrm{H}$, Fukuda H, Yoshida K, Iizuka J, Kobayashi H, Okumi M, Ishida H, Tanabe K (2019) Association between immune-related adverse events and prognosis in patients with metastatic renal cell carcinoma treated with nivolumab. Urol Oncol 37(6):355. https://doi.org/10.1016/j. urolonc.2019.03.003 (e321-355 e329)
27. Yamazaki N, Takenouchi T, Fujimoto M, Ihn H, Uchi H, Inozume T, Kiyohara Y, Uhara H, Nakagawa K, Furukawa H (2017) Phase 1 b study of pembrolizumab (MK-3475; anti-PD-1 monoclonal antibody) in Japanese patients with advanced melanoma (KEYNOTE-041). Cancer Chemother Pharmacol 79(4):651-660

28. Yang F, Paccaly AJ, Rippley R, Davis J, DiCioccio A (2019) Selection of fixed dose $350 \mathrm{mg}$ every 3 weeks (Q3W) cemiplimab (Anti-PD-1) in patients with advanced malignancies based on population pharmacokinetics (PopPK) modelling. ACoP10, Orlando FL, ISSN:2688-3953, Vol 1, S-004. https://www.go-acop. org/assets/ACoP10/documents/ACoP10\%20Combined\%20Abs tracts_2019.pdf

29. Paccaly A, Migden M, Papadopoulos K, Yang F, Davis J, Rippley R, Lowy I, Fury M, Stankevich E, Rischin D (2019) Pharmacokinetic (PK) analysis of weight-based and fixed dose cemiplimab in patients (pts) with advanced malignancies. Ann Oncol 30(suppl_5):v475-v532. https://doi.org/10.1093/annonc/mdz253

30. Feng Y, Wang X, Bajaj G, Agrawal S, Bello A, Lestini B, Finckenstein FG, Park J-S, Roy A (2017) Nivolumab exposure-response analyses of efficacy and safety in previously treated squamous or nonsquamous non-small cell lung cancer. Clin Cancer Res 23(18):5394-5405

31. Patnaik A, Kang SP, Rasco D, Papadopoulos KP, Elassaiss-Schaap J, Beeram M, Drengler R, Chen C, Smith L, Espino G, Gergich K, Delgado L, Daud A, Lindia JA, Li XN, Pierce RH, Yearley JH, Wu D, Laterza O, Lehnert M, Iannone R, Tolcher AW (2015) Phase I study of pembrolizumab (MK-3475; anti-PD-1 monoclonal antibody) in patients with advanced solid tumors. Clin Cancer Res 21(19):4286-4293. https://doi.org/10.1158/1078-0432. CCR-14-2607

32. Bajaj G, Wang X, Agrawal S, Gupta M, Roy A, Feng Y (2017) Model-based population pharmacokinetic analysis of nivolumab in patients with solid tumors. CPT Pharmacometr Syst Pharmacol 6(1):58-66. https://doi.org/10.1002/psp4.12143

33. Ahamadi M, Freshwater T, Prohn M, Li CH, De Alwis DP, De Greef R, Elassaiss-Schaap J, Kondic A, Stone JA (2017) Modelbased characterization of the pharmacokinetics of pembrolizumab: a humanized anti-PD-1 monoclonal antibody in advanced solid tumors. CPT Pharmacometr Syst Pharmacol 6(1):49-57. https://doi.org/10.1002/psp4.12139

34. Eigentler TK, Hassel JC, Berking C, Aberle J, Bachmann O, Grünwald V, Kähler KC, Loquai C, Reinmuth N, Steins M (2016) Diagnosis, monitoring and management of immune-related adverse drug reactions of anti-PD-1 antibody therapy. Cancer Treat Rev 45:7-18

35. Migden M, Khushalani N, Chang A, Rischin D, Schmults C, Hernandez-Aya L, Meier F, Schadendorf D, Guminski A, Hauschild A, Wong D, Daniels G, Berking C, Jankovic V, Stankevich E, Booth J, Li S, Lowy I, Fury M, Lewis K (2019) Primary analysis of phase 2 results of cemiplimab, a human monoclonal anti-PD-1, in patients with locally advanced cutaneous squamous cell carcinoma (P6015). J Clin Oncol 37(suppl; abstr 6015). https://doi. org/10.1200/JCO.2019.37.15_suppl.6015

36. Yamamoto N, Nokihara H, Yamada Y, Shibata T, Tamura Y, Seki Y, Honda K, Tanabe Y, Wakui H, Tamura T (2017) Phase I study of nivolumab, an anti-PD-1 antibody, in patients with malignant solid tumors. Invest New Drug 35(2):207-216

37. Yamazaki N, Kiyohara Y, Uhara H, Uehara J, Fujimoto M, Takenouchi T, Otsuka M, Uchi H, Ihn H, Minami H (2017) Efficacy and safety of nivolumab in Japanese patients with previously untreated advanced melanoma: a phase II study. Cancer Sci 108(6):1223-1230. https://doi.org/10.1111/cas.13241

Publisher's Note Springer Nature remains neutral with regard to jurisdictional claims in published maps and institutional affiliations. 